\title{
'To Beijing and Back': Reflections on the Influence of the Beijing Conference on Popular Notions of Women's Empowerment in Ghana
}

\author{
Takyiwaa Manuh and Nana Akua Anyidoho
}

\begin{abstract}
The 1995 Fourth World Conference on Women in Beijing was a pivotal moment for legitimating women's rights work in Ghana and served as a powerful framing for women's empowerment. This article explores the Beijing conference and examines its influence on popular notions of and efforts to promote women's empowerment. We argue that the discursive context provided by the conference shaped popular narratives about women directly and also through its influence on the ideas and practices of public institutions and civil society. There is greater acceptance that women have rights that should be promoted and protected, and that there should be institutions and systems to which they have recourse. However, significant work remains to be done in tackling the resistances and tokenism that continue to dominate public discourses and actions to advance gender equality. Further efforts to advance women's empowerment and gender equality in Ghana must therefore build on the legacy of the Beijing conference.
\end{abstract}

\section{Introduction}

In the aftermath of the Fourth World Conference on Women in 1995, the term 'Beijing!' became a catchphrase in Ghana. The young woman in the university, determined to make her point in the classroom, was hailed or shouted down with 'Beijing! Beijing!'. Similarly, the woman at a male-dominated meeting in a government department who said anything that smacked of feminism heard the rumble from male colleagues, 'You Beijing people again!'. In the cries of 'Beijing!', 'Beijing!' then, was a greater awareness of women's struggle for more space and voice. The term held within itself a range of reactions to this fact of women's increased presence - from friendly teasing, to derision, to grudging admiration. Beyond providing the catchphrase of the day, we have to understand the United Nations (UN) Women's Conference in 1995 as a significant moment for women's empowerment in the popular domain in Ghana which, at the same time, echoed pre-existing ideas around women's power.

While there is a rich literature conceptualising empowerment and investigating its interpretation and processes in policies, programmes and institutions, relatively little has been done on popular conceptions of women's empowerment in Ghana. ${ }^{1}$ Admittedly, there have been insightful publications on the efforts of the women's movement in Ghana to advance gender equality and women's rights (Adomako Ampofo 2008; Fallon 2008; Tsikata 2009). However, these civil society organisations do not comprise the whole of the public domain even though, undoubtedly, their work affects ideas therein. Nonetheless, gender equality is not only a question of state policies or of the activism of women's groups and movements, but also relates to the values, attitudes, behaviours and relationships among citizens, within communities, and in society at large. As is well known, the public domain is frequently a site of misinformation about, and resistance to, rights (Anyidoho 2011). The public domain is also the setting for behaviours and acts that perpetuate inequality, such as discrimination and abuse. Thus, change in discourse and behaviour in the public domain is one gauge of success for the efforts of policymakers and activists (Gadzekpo 2009).

Moreover, popular ideas can influence the work of institutions and organisations and for this reason also, 
are worth studying. This article therefore focuses on popular discourses while retaining as a backdrop the institutions and organisations that influence, and are in turn influenced by, these popular notions.

This article is written from our standpoint as researchers and activists in Ghana. We thus base our analyses on both scholarship and also on 'local knowledge' (cf. Geertz 1983) of various kinds, including that derived from observation and lived experience. In addition, the article draws on the experiences of three researcher-activists at the forefront of the promotion of women's empowerment in Ghana during and after the Beijing conference. Their perspectives, elicited through interviews, served to confirm, clarify and challenge our own memories and analyses. Rose Mensah-Kutin is Director of ABANTU for Development and former convenor of the Network for Women's Rights in Ghana (NETRIGHT). Vicky Okine, currently with the Alliance for Reproductive Health Rights, worked for almost a decade with the National Council on Women and Development (NCWD), the erstwhile national machinery for women. In 1995, she participated in the Beijing conference as a representative of civil society, as did Dorcas CokerAppiah of the Centre for Gender Studies and Human Rights Documentation (The Gender Centre).

The pivotal concept for this article is 'empowerment'. Central to the concept of empowerment is power; thus, empowerment is a process of change of acquiring power from a position of disempowerment. Jo Rowlands (1998) provides an oft-cited typology that encompasses the different kinds of power sought through the process of empowerment - the capacity to act on decisions ('power to'), confidence or self-esteem ('power within'), and the power of collective action ('power with'). Rowlands' formulation roughly corresponds to Batliwala's (2007) dimensions of empowerment: resources (power to), agency (power to, power with, power within) and outcomes (power to). The Pathways of Women's Empowerment Research Consortium (in which both authors participated) conceptualised empowerment as having multiple dimensions (including social, political, economic) and involving multiple pathways. ${ }^{2}$

When a complex concept such as empowerment is taken up in development policy and practice, and is used ubiquitously, its meaning becomes diffused; it becomes a buzzword - or as Cornwall (2010) terms it, a 'fuzzword' - into which policymakers, development practitioners, activists and ordinary citizens can invest their own meanings. This happened with the term 'Beijing' which had overlaps with the ideas contained in the concept of 'empowerment'. In this article we try to unpack what 'Beijing' meant in popular conception and we argue that while, prior to the Beijing conference, empowerment largely meant economic power (read: microcredit programmes for women), promoted by the women in development (WID) approach of the NCWD, after Beijing it also became about agency in personal, social and political relationships of power between the state and women, and between men and women. In other words, it was about the representation and visibility of women in the political, social and personal domains in Ghanaian society.

\section{Explaining the salience of the Beijing conference in the public mind}

Why did the Beijing conference and the ideas coming out of it make such an impact on the Ghanaian public? The answer to this question has several parts.

First, Beijing was significant for Ghanaians as a major international event, a moment where some agreements and actions could be taken on a common global problem of gender inequalities under the convening power of the UN. Public awareness in Ghana of the Beijing conference derived from several sources. Unlike the earlier international women's conferences (Mexico 1975, Copenhagen 1980 and Nairobi 1985), there was broader understanding and knowledge about the Beijing conference among a spectrum of people and organisations worldwide, including civil society organisations in Ghana that were able to sponsor individuals to attend the conference alongside the official government delegation, as Rose MensahKutin confirmed:

At the time of Beijing, there was broader understanding and knowledge about these meetings. Coupled with the fact that some people had already had training... there was some level of awareness of the importance of this meeting... [And] for the first time, so many people were able to attend the conference. ${ }^{3}$

Again, the fact that an African woman, Gertrude Mongella of Tanzania, chaired the conference also generated interest and coverage around Africa. There was the feeling that although the location of the conference was in Asia, the leadership was African. This generated a synergy among the Asian and African participants who felt that the conference 
was addressing their concerns, unlike earlier meetings that participants from the global South perceived to have been dominated by the West.

For these reasons, the Ghanaian media recognised that the conference merited coverage. No doubt the fact that the government delegation was led by the then first lady, Nana Konadu Agyemang-Rawlings, who was also president of the 31 st December Women's Movement (DWM), gave the media added reason to report closely on the conference. Thus, the event was registered in the minds of Ghanaians by its extensive coverage, as many journalists accompanied the official Ghanaian delegation, and daily reports were filed from Beijing and carried nationwide by the government-owned newspapers and television station. ${ }^{4}$ In addition to these local sources, China also engaged in a media blitz to counter the negative publicity it was receiving on its human rights record and on its ability to host the conference.

All this meant that Ghanaians were paying attention to what was going on in the Beijing conference. However, what made 'Beijing!' part of popular culture was the interpretation that the Ghanaian public gave to the ideas coming out of the conference. And to explain these interpretations, one has to make reference to political and historical contexts.

\section{Interpreting 'Beijing!' in the Ghanaian context}

Ghanaian activists generally agree that the conference was a momentous event in bringing women's rights and empowerment ideas to public attention and in invigorating the struggle for advancement of these issues. However, there is no denying that there was also scepticism from members of the public that the themes of the Beijing conference, and the concept of women's rights in general, were not part of 'Ghanaian culture', but a derivative discourse that was, in any case, unnecessary. Such persons would make reference to the value that Ghanaian 'tradition' accords women as the source of wisdom and as behind-the-scenes powerbrokers. They might then evoke the iconic image of Yaa Asantewaa, the warrior-queen on the cusp of colonial rule in Asante, who confronted the full force of British imperialism by rallying her people to war (Boahen 2003; Manuh 2007a). Ironically, a critical analysis of Yaa Asantewaa's heroism casts doubt on how much her actions advanced women as a group. After all, her famous declaration that cowardly men who did not want to fight against the British should exchange their loin cloths for her under-garments (Boahen 2003: 118) reflected gendered stereotypes of the brave warrior-man versus the reticent female. And indeed in popular culture, 'Yaa Asantewaa' is used, often mockingly, to refer to a woman who shows strength or power in ways normally associated with men. More positively, Yaa Asantewaa may be seen as a symbol of women's power and, by extension, the tolerance of a society that would glorify such a singular woman.

These popular allusions are reinforced in academic writings that argue for recognition of the complementarities between women and men historically. The complementary thesis posits that women and men were 'separate-but-equal', and highlights women's contributions in trade and production; the recognition and expectation of their economic autonomy; their political and military roles; their rights to their own property, to sexual satisfaction, and to sever unsatisfactory relationships with men (Arhin 1983; Hagan 1983; Aidoo 1985).

In these writings, the distance between women's lives in the past and their contemporary reality is attributed to colonialism with its imposition of Victorian values, and new social forces and economic relationships that disrupted the autonomy and freedoms that existed in pre-colonial Ghanaian societies and subordinated Ghanaian women as a whole to new cultural and religious norms, even as a minority of women gained new statuses and rights (Manuh 1984; Tsikata 1989; Anyidoho, Dzorgbo and Prah 2013).

As happened elsewhere on the continent, during the struggle for independence, women's 'special interests' were put on hold while a more 'national' cause was being fought. And Ghanaian women may have felt that they were being rewarded for their patience when Kwame Nkrumah, the first president, proceeded to appoint women to cabinet positions and to set a quota for women in parliament. Yet here again, national interest - this time nationbuilding and development - took priority (Tsikata 1989). Even women's attempt to mobilise through the National Council of Ghanaian Women was co-opted into the service of party politics as it was transformed into the women's wing of Nkrumah's Convention People's Party. If women's lot improved, it was often as a result of social provisioning for the entire population, rather than any sustained commitment to women's empowerment and gender equality. That being said, the next 20 years of rule by various military regimes, after Nkrumah's overthrow in a coup d'état in 1966, did little for women's advancement as a group. 
The increasing economic stagnation during these regimes, and their failure to provide goods and services, resulted in political leaders turning on their own citizens, and on women in particular. Through the military regimes from the 1970s and 1980s, traders were blamed for high prices, the hoarding of goods and services, and corruption, kalabule, and were subjected to various punitive measures. The 1979 public destruction of Makola market, the trading place dominated by women (Bentsi-Enchill 1979; Robertson 1983), signalled the public effort to physically uproot these social vices, and to appease urban workers (mostly male) who complained of low wages and declining purchasing power and who resented the women they perceived to have outflanked them in the pursuit of wealth and who no longer respected their husbands and men in general (Manuh 1993). This perception of market women was paradoxical; while Ghanaian women were expected to be hardworking and enterprising, they were also to confine themselves to 'non-threatening' activities and spaces and not attempt to upstage men.

Nonetheless, within different historical eras in Ghana, there have been examples of women who have stepped out of their designated spaces. For instance, opportunities for formal education in the period of colonial rule and beyond created opportunities for increasing segments of the population, including women and girls, to obtain education and employment in the then growing public sector (Manuh 1984). The ten women appointed to the parliament of the first postindependence government are an example of such women who have earned a place in Ghanaian history (Manuh 1991; Tsikata 1989). There were also examples of women's organising for their own welfare and advancement even during the military periods that we have described as being unfriendly to women (Tsikata 1989). The DWM is worth mentioning here. For more than a decade before Beijing, the DWM had dominated the space for women's work in Ghana. Labelling itself variously as a non-governmental organisation (NGO) and as 'the women's wing of the revolution', it called on Ghanaian women to participate in national development (Manuh 1993). It established farms and income-generating projects around Ghana, especially in rural areas, aimed at women's economic empowerment. The picture of members in their red berets, singing and dancing, has remained with an older generation of Ghanaians as it was an image constantly beamed on national television as cameras followed its president and first lady on tours to various project sites around the country.
The movement's links to state power, the donor funds it monopolised, and the mobilisation strategies employed gave it high exposure and helped it to spread its message.

It was also during a military government that the NCWD was set up in 1975, following a UN General Assembly Resolution. While its status as a council meant that it was not part of the government bureaucratic set-up, the NCWD was essentially an arm of government. Members of the board were appointed by the government, and included civil service officials, and it was funded from government grants. Its mandate was to provide policy advice, coordinate and evaluate civil society and government programmes related to women, and to report to government (Mensah-Kutin 2000).

The setting up of the NCWD was in part a result of advocacy locally for state attention to and institutionalisation of gender concerns into policymaking (Mensah-Kutin 2000). But it was also a consequence of the phenomenon of an increasing global advocacy on women's equality, evidenced in part by the declaration of the UN International Women's Year in 1974 and the First UN International Conference on Women in 1975. Thus, the NCWD played a major role in bringing home ideas that emanated from the global discourse on women. From its onset, it was instrumental in diffusing the development paradigm of women in development, mainly through income-generating interventions. We can thus think of the NCWD and civil society actors as antennae to global discourses that were then relayed through their programmes and activities.

How did 'women's empowerment' as a term and an idea come into the public domain in Ghana? Dorcas Coker-Appiah provides her perspective:

It started coming up after the Mexico conference, but I think it was one of those words that not many people, apart from those in government, paid much attention to... It was one of those things borrowed from outside but our understanding of it had not been deeply analysed. ${ }^{5}$

Subsequently, Beijing made empowerment an important symbol and reference point for activists. At the same time, popular interpretations of Beijing reflected a change in discourse that showed the limits of the efforts of the DWM and the NCWD, important as these were, in promoting women. To illustrate with the DWM, its links to the ruling military government and its leadership by the 
first lady tinged its rhetorical use of 'women's empowerment'. The organisation borrowed from the populist revolutionary and anti-imperialist stance of the military government with its stated intent to flatten the social strata, and expand the space for popular expression. But the movement's espousal of women's empowerment was mostly in the economic realm and did not challenge prevailing gender relations. Indeed the organisation's president was known to admonish women not to use their wealth to 'disrespect' men (Manuh 1993). Again, even if only discursively, the efforts of the DWM were geared towards a 'national project' that was vaguely defined, making women's empowerment an instrument to some higher cause. Moreover, the DWM and its president dominated the landscape, crowding out other women and organisations. Thus, while some members of the DWM undoubtedly became influential, it is doubtful the extent to which the movement advanced women's empowerment in a real sense for the majority of its members and for Ghanaian women in general.

By comparison, Beijing represented an opportunity for all women, regardless of political background, age, social standing or geographic location. And herein lay the difference in connotation between the old label 'Yaa Asantewaa' and the new label of 'Beijing'. Yaa Asantewaa can be said to represent individual achievement, while Beijing referenced the collective. In other words, society can tolerate a few non-conformist women or Yaa Asantewaas, but for those who were really hostile towards women's empowerment, 'Beijing' was about more than individual self-assertion as occasional and incidental occurrences. Thus, when a man jokingly exclaimed, 'The Beijing women are coming!' at the sight of a gender activist entering the room, the statement would be tinged with alarm at the possibilities of the collective will of women gathered behind the cause of women's empowerment. Again, Beijing was about a diffusion of ideas that would affect people's lives in real ways, invading personal spaces and relationships. In the past there may have been iconic women, but these women were not your wife, daughter or female co-worker. 'Beijing' contained within it the threat of disruption of social relations in ways that had perceptible implications for the dynamics of intimate relationships.

In sum, Ghanaian women have always spoken up, usually individually, and in personal spaces. Women have also joined hands to work to change undesirable situations for themselves or their communities. What Beijing provided was a discourse or framework within which these demands could be articulated:

The idea of struggle and change is always there, but then Beijing or these UN conferences provided a frame of reference that made it easy for people to come out easily to say that this is what we want... The Platform for Action was a document that was widely disseminated, and that reflected issues that women could identify with in their locality. They were picked up by government institutions and NGOs. ${ }^{6}$

So large did Beijing loom in the public consciousness that even occurrences that were not uncommon before the Beijing Platform for Action (BPfA) were now seen through its lens. As Rose Mensah-Kutin narrated:

If you were a woman, and your man wasn't taking care of your children, and you went to the public tribunal [court], it was going to be interpreted as being influenced by Beijing. ${ }^{7}$

It must, however, be noted that the import of Beijing was lost on some, or conveniently ignored:

It was actually post-Beijing that really raised the consciousness... but unfortunately the consciousness was somehow negative, in the sense that people began to use it as a joke... I think to some extent, even though people began to realise that there were issues around women's empowerment, unfortunately, the whole issue of the conference and its outcome became one big joke for some men. ${ }^{8}$

With this mindset, whatever steps individual women were taking to demand their rights could be dismissed as evidence of their having been influenced by 'some disgruntled women who did not know what they were about', said Mensah-Kutin. ${ }^{9}$

However, it was difficult to ignore or to wish away the change that Beijing had brought in popular conceptions and in civil society activism. It is acknowledged by civil society organisations that Beijing gave a boost to work on women's rights issues in Ghana and to the public's awareness of this work. Gender activists and organisations working with women found that the Beijing conference gave them a new direction or approach (whether they had been physically present in Beijing or not), and after the conference some organisations were set up specifically to promote women's rights across a range of thematic areas. 
The Beijing conference and its outcomes also gave activists a vocabulary to articulate what they were already involved in as the advocacy of women's rights and empowerment. For instance, while organisations such as Women in Law and Development

(WILDAF) worked on women's legal rights and other organisations worked on microcredit and incomegenerating activities for women, this work was not framed in terms of the economic and social rights to which women were entitled. However, after Beijing, a number of organisations re-centred their work around one or some of the 12 critical areas in the BPfA that had local resonance.

Beijing gave greater confidence to these activists, as it did to women in the public eye. One activist recalled how difficult it was before Beijing to go to meetings where one might be the only woman present, and to stand up as a gender activist in that space occupied by men and in which gender equality was considered a dirty word. The result of attending the Women's Conference and the preparatory meetings was that women activists became more confident and more sophisticated in making rights demands, supported by the shift from the WID to the gender and development (GAD) paradigm which contained within it an analysis of gendered power relations. Importantly, Beijing as a UN conference also highlighted the role of institutions and mechanisms for ensuring gender equality. Thus, behind each woman or organisation which made demands in the name of Beijing was the presence of the state, however notional, and of a global movement.

\section{The aftermath of Beijing}

Ghanaian activists who had participated in the conference returned home energised. Beijing for them 'was a momentous occasion in terms of galvanising what people knew about women's empowerment and preparing them to do something on the ground'. ${ }^{10}$ They found that their work was made both easier and more difficult by the assimilation of 'Beijing' into everyday vocabulary, and the ways in which the term was used and understood were varied and complicated by the contradictions of public attitudes and beliefs about gender relations. For instance, Mensah-Kutin recalls that when directed at activists such as herself, the label 'was doubled-edged... it was a way of acknowledging what you were doing, but at the same time, it was a way of deflating you, making you feel that you were trying to act outside of (accepted norms)'. ${ }^{11}$ Thus Beijing was a way of acknowledging 'that the discourse of women's empowerment was gaining ascendancy. They were unconsciously taking note of the fact that women were making demands'. ${ }^{12}$

Today, Beijing is a part of popular memory in Ghana. According to Vicky Okine:

Those who belong to that generation still remember Beijing because it was a landmark. And I am inclined to think that people still remember what it stood for. ${ }^{13}$

However, the enduring power of Beijing can be determined by whether the momentum for women's empowerment has been sustained and built on.

For activists, no moment since Beijing has been quite as seminal in pushing the frontiers of women's empowerment nor has any other event had quite the power to capture popular imagination. That is not to say, however, that there have not been important moments in Ghana in terms of the advancement of women's causes. After Beijing, some forums were organised both by the NCWD and a few civil society organisations to analyse the BPfA and to begin to translate the commitments into actionable programmes. The Gender Centre, for example, was established around this period, and it took up anti-violence work as a critical issue in the Ghanaian context. Their advocacy work, coalition building, and the nationwide study that they conducted in 1998 on violence against women and girls, were all instrumental in the establishment by the state of the Women and Juvenile Unit (WAJU) in the Ghana Police Service, and ultimately to the preparation and advocacy of the Domestic Violence Bill which was guided and pushed for by a coalition of women's groups, the National Coalition on Domestic Violence Legislation in Ghana. This process, which culminated in the passage of the Domestic Violence Act in 2007, was accompanied by much public debate and visibility of women's groups. The process of putting together a Women's Manifesto was also another example of the strength of coalition building and advocacy and was again accompanied by media attention and public awareness. ${ }^{14}$

In 2005, when we celebrated Beijing+10 (and, incidentally, when the Pathways of Women's Empowerment began), women's empowerment and gender mainstreaming were still buzzwords. The Millennium Development Goals (MDGs) dominated development discourse, although more attention was focused on MDGs 4 and 5 on infant and maternal mortality respectively, than on MDG 3, on gender 
equality and empowerment. In Ghana, as elsewhere in the developing world, gender policies were formulated that often did not translate into concrete operational plans, while in the main policies continued to be gender-blind.

So where are we now, 20 years after the Beijing conference? As a society, we have come to a stage where there is familiarity with the idea of women's empowerment. One activist recalls mooting the creation of a gender unit to her immediate boss in a government ministry some decades ago. ${ }^{15}$ His response was that such a unit would be an island. Now, she says, no one would oppose the idea of a gender unit, particularly as gender mainstreaming is ostensibly the core principle guiding gender and development work within the government bureaucracy itself. Interestingly, the idea of gender mainstreaming has given rise to another catchphrase - 'gender balance'. In popular use, this is usually a call for some form of female representation. Usually, the result is mere tokenism, as people tend to feel 'gender balance' has been achieved if one or two women are included in the mix.

However, an attempt to more comprehensively evaluate our progress on empowerment and gender equality reveals a gap between rhetoric and reality. In March 2015 at the 59th Session of the Commission on the Status of Women, Ghana's Minister of Gender, Children and Social Welfare reported that the country had made substantial progress on women's empowerment and gender equality by folding the MDGs and the BPfA into national development plans. She mentioned in particular the areas of women's poverty, the gender gap in enrolment in formal education, women's health, and women's representation in public office as areas in which there had been significant achievements through policy measures and programmes such as Livelihood Empowerment Against Poverty (an aspect of the national social protection strategy) and a number of bills and legislative instruments currently before the legislature, including an Affirmative Action Bill, a Property Rights of Spouses Bill, and the Domestic Violence Legislative Instrument.

This picture of steady and noticeable gains is in contrast to that of organised women's groups in Ghana, notably NETRIGHT, a group of civil society organisations working on women's rights issues that has since 1999 been engaged in the Beijing review processes and that produces an NGO Shadow
Report on the BPfA. NETRIGHT has been critical of the disconnect between the MDGs and the BPfA (NETRIGHT 2015). Participants of a NETRIGHT workshop to validate findings of a national consultation on Beijing+20 were less sanguine about progress in the very areas mentioned in the minister's speech at the UN session. While they acknowledged some improvement in reduction in women's poverty, they pointed to the constraints in access to and control of land, and a lack of policy to address this, as a major hurdle to further addressing poverty; in education, the wide gender disparity in enrolment in science and technology programmes was reported; accessibility of health care (and particularly family planning services) was mentioned as a grave concern; and on the topic of women's power and decision-making, participants reported low, almost insignificant, levels of representation in local governance and in appointments to public office. Further, respondents mentioned an environment of partisanship as a major obstacle to advancements in all these areas (NETRIGHT 2015).

On a continental level, the African heads of state have adopted a Common African Position (CAP) on the post-2015 agenda that rests on six pillars, one of which is human-centred development. Hidden within this pillar is a focus on gender equality and women's empowerment, which African ministers of gender argued, in a statement issued on 6 February 2014, should be made a separate pillar. They mentioned the importance of decent work and a living wage for women in both informal and formal sectors as central to this proposed pillar, as well as redistribution and remuneration of unpaid care work. They also raised questions of public and private investments in agriculture to achieve food security and nutrition; transformative gender parity in decision-making positions across all levels in politics and in public and private sectors; security for women and girls in conflict and post-conflict countries, and so on. Unfortunately, this separate pillar, akin to the standalone goal on gender equality that feminists and activists are demanding in the post-2015 agenda, was not achieved in Africa. However, the issues raised by the ministers, which reflect the positions of activists around Africa, remain pertinent and pending and constitute an agenda for work and mobilisation on women's empowerment at national, regional and continental levels by women's rights organisations, activists and their constituencies. As Rose MensahKutin concludes, 'there is a recognition that you can't move backwards... people may be uncomfortable with [women's empowerment], but it has come to stay. ${ }^{, 16}$ 


\section{Notes}

1 Pereira's (2014) edited volume discusses women's sexuality and its intersection with empowerment in various contexts (including in storytelling and in the media) across the global South. For the Ghana case, exceptions include Adomako Ampofo and Asiedu (2012) on conceptions of women and women's empowerment in popular culture. In discussing the activities of the women's movement and rights-promoting organisations in Ghana, Adomako Ampofo (2008), Anyidoho (2011), Fallon (2008) and Tsikata (2009) make mention of popular ideas about women's rights, equality and empowerment, but in none of these cases is public discourse the focus of their writing.

2 See www.pathwaysofempowerment.org.

3 Interview by the authors, 16 February 2010.

4 There was only one TV station at the time and the airwaves were yet to be liberalised.

5 Interview by the authors, 16 February 2010.

6 Interview with Rose Mensah-Kutin, 16 February 2010.

\section{References}

Adomako Ampofo, A. (2008) 'Collective Activism: The Domestic Violence Bill Becoming Law in Ghana', African and Asian Studies 7.4: 395-421

Adomako Ampofo, A. and Asiedu, A.M. (2012) 'Changing Representations of Women in Ghanaian Popular Music: Marrying Research and Advocacy', Current Sociology 60.2: 258-79

Aidoo, A.A. (1985) 'Women in the History and Culture of Ghana', Research Review 1: 14-51

Anyidoho, N.A. (2011) Ghana Review of Rights Discourse, Research Note, Norwegian Centre for Human Rights, University of Oslo

Anyidoho, N.A.; Dzorgbo, D-B. and Prah, M. (2013) 'Social Relations', in Ghana Social Development Outlook, Legon: Institute of Statistical, Social and Economic Research (ISSER)

Arhin, K. (1983) 'The Political and Military Roles of Akan Women', in C. Oppong (ed.), Female and Male in West Africa, London: George Allen and Unwin

Batliwala, S. (2007) 'Putting Power Back into Empowerment', Open Democracy, http://opendemocracy.net/article/putting_ power_back_into_empowerment (accessed 5 February 2010)

Bentsi-Enchill, N-K. (1979) 'Losing Illusions at Makola Market', West Africa 3242 (Sept): 1589-92

Boahen, A.A. (2003) Yaa Asantewaa and the AsanteBritish War of 1900-1, Accra and Oxford: Sub-Sahara Publishers and James Currey
7 Interview with Rose Mensah-Kutin, 16 February 2010.

8 Interview with Dorcas Coker-Appiah, 16 February 2010.

9 Interview by the authors, 16 February 2010.

10 Interview with Rose Mensah-Kutin, 16 February 2010.

11 Interview by the authors, 16 February 2010 .

12 Interview by the authors, 16 February 2010.

13 Interview by the authors, 17 February 2010.

14 These processes have been researched and written about. For example, Tsikata (2009) describes the significance of these events in terms of what was achieved both for institutionalising women's empowerment and in bringing the work of activists to public attention. Adomako Ampofo (2008), Fallon (2008) and Manuh (2007b, 2007c) have covered the campaign for the passage of the Domestic Violence Act.

15 Interview with Rose Mensah-Kutin.

16 Interview by the authors, 16 February 2010.

Cornwall, A. (2010) 'Introductory Overview -

Buzzwords and Fuzzwords: Deconstructing Development Discourse', in A. Cornwall and D. Eade (eds), Deconstructing Development Discourse: Buzzwords and Fuzzwords, Oxford: Practical Action and Oxfam GB

Fallon, K.M. (2008) Democracy and the Rise of the Women's Movements in Sub-Saharan Africa, Baltimore MD: Johns Hopkins University Press

Gadzekpo, A. (2009) "'She Made Me Do It" Discursive Frames and Representation of Spousal Murder in the Ghanaian Press', in K. Cusack and T. Manuh (eds), The Architecture of Violence against Women in Ghana, Accra: Gender Studies and Women's Documentation Centre

Geertz, C. (1983) Local Knowledge: Further Essays in Interpretive Anthropology, New York NY: Basic Books

Hagan, G. (1983) 'Marriage, Divorce and Polygyny in Winneba', in C. Oppong (ed.), Female and Male in West Africa, London: George Allen and Unwin

Manuh, T. (2007a) 'YaaAsantewaa', Encyclopedia of Women in World History, Oxford: Oxford University Press

Manuh, T. (2007b) African Women and Domestic Violence, http://opendemocracy.net/article/5050/ghana_ domestic_violence (accessed 5 February 2010)

Manuh, T. (2007c) 'Doing Gender Work in Ghana', in C. Cole, T. Manuh and S. Miescher (eds), Africa After Gender, Bloomington IN: Indiana University Press 
Manuh, T. (1993) 'Women, State and Society under the PNDC', in E. Gyimah-Boadi (ed.), Ghana Under PNDC Rule, Dakar: CODESRIA Books

Manuh, T. (1991) 'Women and their Organizations during the Period of CPP Rule in Ghana, 19511966', in K. Arhin (ed.), The Life and Work of Kwame Nkrumah, Trenton NJ and Accra: African World Press/SEDCO Publications

Manuh, T. (1984) Law and the Status of Women in Ghana, Addis Ababa: UNECA, ATRCW

Mensah-Kutin, R. (2000) 'The National Machinery for Women in Ghana: An NGO Evaluation', National Machinery Series 3, Accra: Third World Network-Africa

NETRIGHT (2015) 'National Validation Meeting on Beijing+20 Review and Post 2015 Agenda', unpublished report, 8 December 2014, Accra: Network for Women's Rights in Ghana
Pereira, C. (ed.) (2014) Changing Narratives of Sexuality - Contestations, Compliance and Women's Empowerment, London: Zed Books

Robertson, C. (1983) 'The Death of Makola and Other Tragedies: Male Strategies against a Female-Dominated System', Canadian Fournal of African Studies 17.3: 469-95

Rowlands, J. (1998) 'Empowerment and Development', in H. Afshar (ed.), Women and Empowerment, Basingstoke: Macmillan

Tsikata, D. (2009) 'Women's Organizing in Ghana since the 1990s: From Individual Organizations to Three Coalitions', Development 52.2: 185-92

Tsikata, E. (1989) 'Women's Political Organizations 1951-1987', in E. Hansen and K.A. Ninsin (eds), The State, Development and Politics in Ghana, Dakar: CODESRIA Books 